\title{
Influence of Si/Al Ratio on Catalytic Performance of (Co)Mo/Saponite Catalysts
}

\author{
R. G. L eliveld, ${ }^{1}$ T. G. R os, A . J. van D illen, J. W. G eus, and D. C. Koningsberger \\ D epartment of Inorganic Chemistry, D ebye Institute, U niversity of U trecht, P.O. B ox 80083, 3508 TB U trecht, The N etherlands
}

R eceived February 7, 1999; revised A pril 7, 1999; accepted A pril 7, 1999

Theinfluence of the Si/Al ratio of the support of $(\mathrm{Co}) \mathrm{Mo}$ /saponite catalysts on the performance in the hydrodesulfurisation of thiophene and hydrocracking of $n$-decane has been studied. The initial thiophene HDS activity of the sulfided Co catalysts increased with increasing support acidity, while with the CoM o catalysts the opposite effect was observed. The large drop in activity at lower $\mathrm{Si} / \mathrm{Al}$ ratios is ascribed to the occurrence of two separate cobalt and molybdenum sulfide phases instead of the "C o-M o-S" phase. In the hydrocracking of $n$-decane both the $\mathrm{Co}$ and the CoM o catalysts displayed an almost linear relationship between the first-order rate constant and the number of Brønsted acid sites. As with zeolite catalysts the Si/AI ratio was also found to affect the product selectivity. At low Si/A I ratios the relative amount of secondary cracking products increased due to a changing balance between the number of cracking and hydrogenation sites. Remarkably, it was found that in the presence of $\mathrm{H}_{2} \mathrm{~S}$ between 423 and $573 \mathrm{~K}$ the $n$-decane conversion passes through a maximum. The observed relation between this "low-temperature" activity and the number of Brønsted acid sites seem to indicate the involvement of both $\mathrm{H}_{2} \mathrm{~S}$ and the acid sites on the support.

(c) 1999 A cademic Press

\section{INTRODUCTION}

$O$ ver the past years clay minerals have attracted increasing attention due to their activity in acid catalyzed reactions (1-4). A $n$ interesting application is their use as support in (mild) hydrocracking catalysts (5). H ydrocracking catalysts are bifunctional catalysts consisting of a hydrogenation component such as a noble metal or metal sulfide, supported on an acidic carrier (6). Typically, hydrocracking catalysts contain zeolites of the faujasite topology (zeoliteY ), which posses favorable acidic properties (7-11). H owever, the limited poresize of zeolites can lead to mass transport limitations of the feed molecules or even exclusion effects in cases of heavy crudes. The "house-of-cards" structure of clay mineralsmight avoid these transport limitations,

\footnotetext{
${ }^{1}$ Present address: A kzo-N obel Chemicals bv., Nieuwendammerkade 1-3, P.O. Box 37650, 1030 BE A msterdam, The Netherlands. E-mail: bob.leliveld@akzonobel.com.
}

which, combined with their acidic properties, makes clays an interesting alternative next to zeolites.

Several studies report on the use of smectite clays in hydrocracking or hydrotreating applications. K loprogge et al . (12), Sharma etal. (13), and Sychev etal. $(14,15)$ reported on the use of pillared montmorillonites in the hydrodesulfurization of thiophene. N oble metal catalysts on clay supports displayed a promising performance in hydroisomerization and hydrocracking of model compounds such as $n$-hexane or n-decane (16-19). Further, tests with gas oil feedstocks were reported by several authors including 0 ccult et al. (20), M onnier et al. (21), and M in (22).

In most of the above-mentioned studies natural clays or clays synthesized under hydrothermal conditions were used. R ecently, our group reported on a novel route of synthesis under nonhydrothermal conditions of a class of $2: 1$ trioctahedral clays called saponites (23). Saponites are layered silicates that are built from octahedral and tetrahedral sheets. The tetrahedral sheets consist of a hexagonal network of primarily $\left(\mathrm{SiO}_{4}\right)^{4-}$ tetrahedra that are interlinked by sharing all three oxygen corners. Substitution of Si by A I creates B rønsted acid sites similar to zeolites. The octahedral layer is sandwiched between the tetrahedral layers and consists of divalent cations octahedrally coordinated by the apical oxygens of the tetrahedral layer and extra hydroxyl groups. In a former study we explored the use of saponites as supports in hydroprocessing catalysts (24). It was found that the lattice of $\mathrm{Co}, \mathrm{Ni}$, and $\mathrm{Zn}$ saponites collapses on exposure to $\mathrm{H}_{2} \mathrm{~S}$ due to sulfidation of the octahedral layer. Clays containing $\mathrm{Mg}$ ions in the octahedral layer are not liable to sulfidation.

In this study the influence of surface acidity of the saponite support on the catalytic performance of sulfided (Co)M o catalysts is reported. The surface acidity is varied by changing the Si/A I ratio of the tetrahedral layers. Since in many hydrocracking operations hydrodesulfurization also is important two model reactions were employed: hydrocracking of n-decane and HDS of thiophene. A lthough the process conditions of these model tests do not resemble commercial operation, the results help to gain a better insight in the effect of a varying Si/A I ratio of the support on 
the catalytic properties. A s already well known with zeolite catalysts (25) it will be demonstrated that in hydrocracking the balance between the number of hydrogenation and acid sites has a pronounced effect on the product selectivity. A dditionally, in both thiophene HDS and n-decane hydrocracking the activity is affected by the Si/A I ratio. With hydrocracking an almost linear relationship is found between the number of Brønsted acid sites and the conversion of n-decane.

\section{METHODS}

\section{Preparation}

Saponites with Mg as the octahedral ion and with varying Si/A I ratios were synthesized at atmospheric pressure as described by Vogels et al. (23). Si/A I gels were prepared from an aqueous solution containing the required amounts of sodium silicate ( $M$ erck p.a., $27 \mathrm{wt} \% \mathrm{SiO}_{2}$ ) and $\mathrm{Al}\left(\mathrm{NO}_{3}\right)_{3} \cdot 9 \mathrm{H}_{2} \mathrm{O}$ and aged at room temperature for $1 \mathrm{~h}$. The gels were diluted with demineralized water and the required amounts of urea and $\mathrm{Mg}\left(\mathrm{NO}_{3}\right)_{2} \cdot 6 \mathrm{H}_{2} \mathrm{O}$ were added. A fter synthesis at $363 \mathrm{~K}$ for $24 \mathrm{~h}$ the saponites were washed with water and ion-exchanged with a $1 \mathrm{M} \mathrm{N} \mathrm{H}_{4} \mathrm{NO}_{3}$ solution. The exchanged samples were dried at $393 \mathrm{~K}$ and calcined in air at $723 \mathrm{~K}$. For reasons of comparison stevensites (no substitution of Si by A I) were also prepared as described above, but starting from a Si gel only.

A fter calcination the products were characterized with $X$-ray diffraction to check that trioctahedral clays had been synthesized. Nitrogen physisorption experiments were carried out to determine the specific surface areas and pore volumes. Typically, M g saponites have surface areas between 500 and $600 \mathrm{~m}^{2} / \mathrm{g}$ and pore volumes between 0.3 and $0.5 \mathrm{cc} / \mathrm{g}$.

Co (4 wt\% CoO) and CoM o (4 wt\% CoO and 11 wt\% $\mathrm{MOO}_{3}$ ) catalysts supported on saponites with Si/A I ratios of 6,26 , and 39 and on stevensites were prepared by incipient wetness (co)impregnation of the various $\mathrm{Mg}$ clays with aqueous solutions containing the required amounts of $\mathrm{Co}\left(\mathrm{NO}_{3}\right)_{3} \cdot 6 \mathrm{H}_{2} \mathrm{O}$ and $\left(\mathrm{NH}_{4}\right)_{6} \mathrm{M} \mathrm{O}_{7} \mathrm{O}_{24} \cdot 6 \mathrm{H}_{2} \mathrm{O}$ (the concentration of the impregnation solutions was varied due to varying pore volumes). The impregnated catalysts were subsequently dried in an air flow at $298 \mathrm{~K}$, dried in stagnant air at $393 \mathrm{~K}$, and calcined at $723 \mathrm{~K}$.

\section{Characterization with EXAFS}

The $\mathrm{Co}$ and CoMo impregnated $\mathrm{Mg}$ stevensites and saponites with a Si/A I ratio of 26 and 6 were characterized with EXAFS at the C $0-K$ and M $0-K$ edges, respectively. The measurements were performed at EXA FS station 9.2 of the SR S at D aresbury (U.K.). The catalyst samples were pressed into self-supporting wafers and mounted in an in situ EXAFS cell (26). A fter sulfidation for $30 \mathrm{~min}$ at $673 \mathrm{~K}(298-673 \mathrm{~K}, 10 \mathrm{~K} / \mathrm{min})$ in a flow of $\mathrm{H}_{2} \mathrm{~S} / \mathrm{H}_{2}(10 / 90)$, spectra were recorded at liquid nitrogen temperature. The $\mathrm{Si}(220)$ double crystal monochromator was detuned to $50 \%$ intensity to minimize the presence of higher harmonics. The measurements were all carried out in transmission mode using optimized ion chambers as detectors.

Standard procedures were used to extract the EXAFS data from the measured absorption spectrum. Normalization was done by dividing the data by the height of the absorption edge and the background was subtracted using cubic spline routines (27). Phase shifts and backscattering amplitudes for calculating the EXAFS contributions were obtained from reference compounds: $\mathrm{CoS}_{2}$ for the $\mathrm{Co}-\mathrm{S}$, $\mathrm{CoO}$ for the $\mathrm{Co}-\mathrm{Co}$, and $\mathrm{MoS}_{2}$ for the Mo-S and Mo-M o absorber-backscatterer pair $(28,29)$. Multiple shell fitting of the EXAFS data was done in $\mathrm{R}$ space. The difference file technique was applied together with phase-corrected Fourier transforms to resolve the different contributions (30). A full optimization of the fits was performed by allowing all parameters of all contributions to vary. Coordination numbers were corrected for the difference in absorberbackscatterer distance between reference compound and unknown assuming an electron mean free path of $5 A^{\circ}$ (31). The X DA P data analysis software program was used (32).

\section{TGA -TPD of A dsorbed n-Propylamine}

TGA and TPD measurements were performed simultaneously using a Perkin EImer TGS-2 microbalance connected to a Fison Instruments quadrupole mass spectrometer. A dsorption was carried out by equilibrating the clay products with n-propylamine vapor at room temperature for $24 \mathrm{~h}$. A weighed amount of sample between 8 and $10 \mathrm{mg}$ was placed in the microbalance and exposed to a $60 \mathrm{ml} / \mathrm{min}$ flow of $\mathrm{N}_{2} / \mathrm{A} \mathrm{r} \mathrm{(10/50).} \mathrm{A} \mathrm{fter} 30$ min the temperature was raised from room temperature to $1173 \mathrm{~K}$ with a linear heating rate of $10 \mathrm{~K} / \mathrm{min}$.

\section{Catalytic Testing}

Catalytic experiments were performed using an automated microflow apparatus. For each experiment 0.25$1.0 \mathrm{ml}$ of catalyst precursor (sieve fraction $150-425 \mu \mathrm{m}$ ) was placed in a quartz lab reactor ( $8 \mathrm{~mm} \varnothing$ ). Prior to the HDS measurements the catalyst was sulfided in a $100 \mathrm{ml} / \mathrm{min}$ flow of $\mathrm{H}_{2} \mathrm{~S} / \mathrm{H}_{2} / \mathrm{A} \mathrm{r} \mathrm{(10/40/50)} \mathrm{while} \mathrm{the} \mathrm{temperature} \mathrm{waslinearly}$ raised from 298 to $673 \mathrm{~K}$ ( $5 \mathrm{~K} / \mathrm{min}$ ) and kept at this temperature for $30 \mathrm{~min}$. Then the flow was switched to $50 \mathrm{ml} / \mathrm{min}$ of 2.4 vol\% thiophene in $\mathrm{H}_{2} / \mathrm{A} \mathrm{r}(45 / 5)$ at atmospheric pressure. A nalysis of the reactor effluent was done using a gas chromatograph equipped with a Chrompack CP-Sil-5 CB column and a FID. The conversion after 2 min on stream was measured and used to calculate a pseudo-first reaction rate constant ( $\mathrm{k}$ ) according to the relation (33)

$$
k=\frac{1}{\tau \cdot \rho} \ln \frac{1}{1-x}
$$


in which $\tau$ is contact time $(\mathrm{s}), \rho$ packing density $\left(\mathrm{kg} / \mathrm{dm}^{3}\right)$, and $x$ conversion. In order to calculate a meaningful rate constant in a second series of experiments the conversion was kept below $90 \%$ by changing the space velocity with the different samples. To prevent slip, the weighed amount of catalyst was diluted with quartz powder (M erck p.a., sieve fraction $200-800 \mu \mathrm{m}$ ) to a total volume of $1.0 \mathrm{ml}$. It was checked that the choice of taking the conversion at $2 \mathrm{~min}$ on stream led to reproducible results.

In order to study deactivation, one of the catalysts was given an oxidative treatment after $6 \mathrm{~h} \mathrm{HDS}$ at $673 \mathrm{~K}$. The catalyst was heated in $\mathrm{O}_{2} / \mathrm{A} \mathrm{r}(10 / 90,100 \mathrm{ml} / \mathrm{min})$ with a rate of $5 \mathrm{~K} / \mathrm{min}$ from $\mathrm{RT}$ to $773 \mathrm{~K}$. A fter cooling down the sample was again sulfided and exposed to thiophene at $673 \mathrm{~K}$.

The catalytic performance in hydrocracking was tested in the conversion of $n$-decane at atmospheric pressure. A fter sulfidation at $673 \mathrm{~K}$ the flow was switched to $50 \mathrm{ml} / \mathrm{min}$ of
2.7 vol\% n-decane in $\mathrm{H}_{2} / \mathrm{H}_{2} \mathrm{~S} / \mathrm{A} \mathrm{r}(44.5 / 0.5 / 5)$. The feed contained $1000 \mathrm{ppm} \mathrm{H}_{2} \mathrm{~S}$ to ensure that the catalyst stayed in its sulfided state. The conversion was measured during $12 \mathrm{~h}$ on stream at $673 \mathrm{~K}$ and a pseudo-first-order reaction rate constant was cal culated according E q. [1] after 2 min on stream. The selectivity of the catalysts at $673 \mathrm{~K}$ was studied at an intended conversion of $40 \%$ (at 2 min on stream) accomplished by changing the contact time. In other experiments the catalysts were cooled down to $423 \mathrm{~K}$ after sulfidation and the conversion curve was measured at every $15 \mathrm{~K}$ at temperatures between 423 and $673 \mathrm{~K}$.

\section{RESULTS}

\section{Characterization}

The sulfided $\mathrm{Co}$ and $\mathrm{COM} O$ catalysts were characterized with EXAFS. Figure $1 \mathrm{~A}$ shows the $\mathrm{k}^{3}$ weighted Fourier
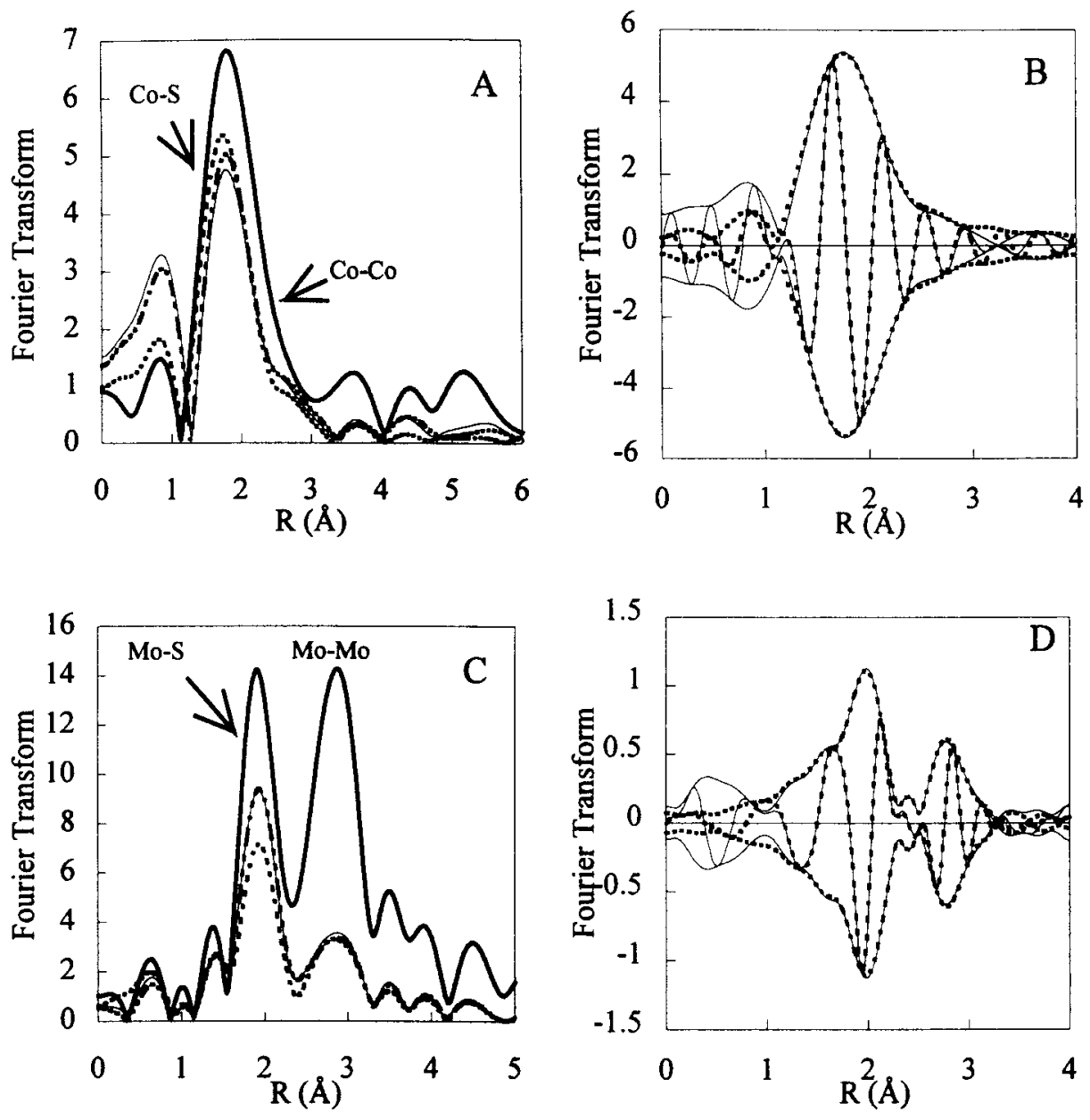

FIG. 1. (A ) Fourier transforms $\left(\mathrm{K}^{3}, \Delta \mathrm{k}=2.90-8.60 \AA^{\circ}\right.$ ) of the $\mathrm{EXA} F \mathrm{~S}$ data obtained at the $\mathrm{C} 0-\mathrm{K}$ edge of $\mathrm{C}$ og $\mathrm{S}_{8}$ ( solid line), sulfided Co/stevensite (thin line), and sulfided Co/saponites with Si/A I ratios of 26 (dashed line) and 6 (dotted line). (B) Fourier transform ( $\left.{ }^{3}, \Delta k=2.90-8.60 A^{\circ}\right)$ and best fit of $\mathrm{Co}$ /saponite with $\mathrm{Si} / \mathrm{Al}=6$. (C) Fourier transforms $\left(\mathrm{K}^{3}, \Delta \mathrm{K}=3.2-12.0 \mathrm{~A}^{\circ}\right.$ ) of the $\mathrm{EXAFS}$ data obtained at the $M$ o-K edge of $M$ oS $\mathrm{S}_{2}(\mathrm{solid}$ line), sulfided CoM o/stevensite (thin line), and sulfided CoM o/saponites with Si/A I ratios of 26 (solid-dotted line) and 6 (dotted line). (D) Fourier transform $\left(\mathrm{k}^{2}, \Delta \mathrm{k}=3.70-14.0 \mathrm{~A}^{\circ}\right)$ and best fit of CoM o/saponite with $\mathrm{Si} / \mathrm{AI}=6$. 


\section{TABLE 1}

Data Analysis Results of Co-K and Mo-K EXAFS of Sulfided Clay Supported Co (4 wt\%) and CoMo (4 and 11 wt\%, Respectively) Catalysts

\begin{tabular}{|c|c|c|c|c|}
\hline Scatterer & $\mathrm{N}$ & $\Delta \sigma^{2}\left(10^{-4} A^{2}\right)$ & $R\left(A^{\circ}\right)$ & $\Delta \mathrm{E}_{0}(\mathrm{eV})^{\mathrm{a}}$ \\
\hline \multicolumn{5}{|l|}{ Co/stevensite } \\
\hline Co-S & 2.8 & 27 & 2.21 & 4.7 \\
\hline $\mathrm{CO}-\mathrm{CO}_{0}$ & 1.0 & -55 & 2.51 & 2.2 \\
\hline \multicolumn{5}{|c|}{ Co/saponite Si/A I = 26} \\
\hline Co-s & 3.0 & 25 & 2.21 & 3.2 \\
\hline $\mathrm{CO}_{0} \mathrm{CO}_{0}$ & 1.0 & -52 & 2.51 & 1.8 \\
\hline \multicolumn{5}{|c|}{ Co/saponite Si $/ \mathrm{A} I=6$} \\
\hline Co-S & 4.0 & 24 & 2.21 & 3.0 \\
\hline $\mathrm{Co}-\mathrm{Co}_{0}$ & 0.6 & -49 & 2.51 & 3.3 \\
\hline \multicolumn{5}{|l|}{ CoM o/stevensite } \\
\hline Mo-S & 5.9 & 31 & 2.41 & 4.0 \\
\hline Mo-Mo & 0.3 & 20 & 2.70 & 0.0 \\
\hline Mo-Mo & 2.3 & 15 & 3.16 & 1.9 \\
\hline \multicolumn{5}{|c|}{ CoM o/saponite Si $/ \mathrm{A} I=26$} \\
\hline Mo-S & 5.8 & 30 & 2.41 & 3.6 \\
\hline Mo-Mo & 0.3 & 19 & 2.70 & 0.4 \\
\hline Mo-Mo & 2.3 & 19 & 3.16 & 1.8 \\
\hline \multicolumn{5}{|c|}{ CoM o/saponite Si/A I = 6} \\
\hline Mo-S & 5.8 & 51 & 2.42 & 0.9 \\
\hline Mo-Mo & 0.4 & 19 & 2.68 & 1.7 \\
\hline Mo-Mo & 2.1 & 15 & 3.14 & 6.1 \\
\hline
\end{tabular}

a The estimated accuracy of the fit parameters is $20 \%$ for $\mathrm{N}$ and $\Delta \sigma^{2}$ and $1 \%$ for $\mathrm{R}$ and $\Delta \mathrm{E}_{0}$.

transform of the Co impregnated stevensite and saponites with Si/A I ratios of 6 and 26. For reasons of comparison the graph also contains the Fourier transform of crystalline $\mathrm{Co}_{9} \mathrm{~S}_{8}$. In $\mathrm{Co}_{9} \mathrm{~S}_{8}$ the peak between 1 and $3 \AA^{\circ}$ consists of both five sulfur neighbors at $2.21 \mathrm{~A}^{\circ}$ and three $\mathrm{Co}$ atoms at $2.51 \AA$. A second $\mathrm{Co}-\mathrm{Co}$ contribution of three $\mathrm{Co}$ neighbors is present at $3.54 \AA$ (28). A s shown in Fig. $1 A$ the amplitude of the Fourier transform of the catalyst samples, notably at the right-hand side ( $\mathrm{Co}-\mathrm{Co}$ ), was reduced compared to the bulk sulfide. This is partly due to a decrease of the $\mathrm{Co}-\mathrm{Co}$ contribution at $2.51 \mathrm{~A}$ (Table 1 ). The low value of 1.0 of the $\mathrm{C}$-C $\mathrm{C}$ coordination number indicates a highly dispersed cobalt sulfide species in accordance with the almost absence of a second peak in the Fourier transform between 3 and $4 \AA^{\circ}$. When it is assumed that no bulk sulfide had been formed the average metal sulfide particles contain about $2 \mathrm{Co}$ atoms. The low number of sulfur neighbors, between three and four, suggests that at least part of the $\mathrm{Co}$ atoms remains coordinatively unsaturated. It was not possible to incorporate a $\mathrm{CO}-\mathrm{O}$ contribution in the fit. The quality of the fits is demonstrated in Fig. 1B, which presents the Fourier transform of measured data of the saponite sample with Si/A I = 6 together with the best fit.

In Fig. 1C the Fourier transforms are shown of the data obtained at the M O-K edge of the sulfided CoM o catalysts together with that of crystalline $\mathrm{MoS}_{2}$. The second shell peak between 2.5 and $3.2 \mathrm{~A}^{\circ}$ is due to Mo backscatterers at $3.16 \mathrm{~A}^{\circ}$ and its amplitude is a direct indication of the $\mathrm{MOS}_{2}$ dispersion (34). The low Mo-Mo coordination number of about 2 (Table 1) points to molybdenum sulfide slabs containing on average about three or four molybdenum atoms per particle. A ccording to a simple hexagonal model, as recently reported by Shido and Prins, neglect of distortions at the edges of small $\mathrm{M} \mathrm{OS}_{2}$ slabs can lead to an underestimating of the particle size (35). In analogy with an earlier study on highly dispersed $\mathrm{M} \mathrm{OS}_{2}$ /alumina catalysts (34), it was tried to include a M 0-O contribution at $2.0 \AA^{\circ}$ in the fit. A Ithough the quality of the fit improved, the M o-O contribution was statistically not significant. D ata analysis did reveal a second M o-M o contribution at $2.7 A^{\circ}$. The latter was also found in a former study on the sulfidation of $\mathrm{M} \mathrm{OO}_{3}$ catalysts supported on alumina and was ascribed to the presence of molybdenum sulfide dimers (36).

\section{$\mathrm{H}$ ydrodesulfurization of Thiophene}

Figure $2 \mathrm{~A}$ shows the conversion of thiophene over the Co catalysts during $6 \mathrm{~h}$ on stream at $673 \mathrm{~K}$ measured at a gas space velocity of $3000 \mathrm{~h}^{-1}$. The initial activity slightly increased with decreasing Si/A I ratios. Except for the weakly acidic stevensite all catalysts suffered from deactivation and reached similar levels of conversion (60-70\%) after $6 \mathrm{~h}$ of reaction. A fter an oxidative treatment the conversion could be restored to near its initial value, pointing to deactivation due to oligomerization and/or coke formation over the acid sites. Similar observations were made with the CoM o catalysts.

Figure $2 \mathrm{~B}$ presents the rate constant $\mathrm{k}_{\mathrm{HDS}}$ after 2 min on stream of the $\mathrm{Co}$ and $\mathrm{CoM} O$ catalysts versus the number of acid sites determined with TPD -TG A of n-propylamine adsorbed on the unloaded supports. $N$ ote that to calculate the first-order rate constant $\mathrm{k}_{\text {HDS }}$ using $\mathrm{Eq}$. [1], a second series of experiments was performed in which the conversion was lowered by measuring with a higher space velocity $\left(12,000 \mathrm{~h}^{-1}\right)$. The amount of $\mathrm{n}$-propylamine desorbing from saponites between 615 and $725 \mathrm{~K}$ can be used to quantify the number of catalytically active $B$ rønsted acid sites as demonstrated by $\mathrm{G}$ orte and coworkers $(37,38)$. The application of this technique to the determination of the surface acidity of synthetic saponites is discussed elsewhere (39). A s Fig. 2B displays with the $C o$ catalysts a small beneficial effect of the support acidity on the HDS acidity was observed. The saponites all displayed a significant higher activity than the stevensite $\left(k_{\text {HDS }}\right.$ increases from $2.3 \mathrm{dm}^{3} / \mathrm{kg} \cdot \mathrm{s}$ for the stevensite to $3.5 \mathrm{dm}^{3} / \mathrm{kg} \cdot \mathrm{s}$ for the saponite with $\mathrm{Si} / \mathrm{AI}=6$; estimated accuracy in $\mathrm{k} \pm 7 \%$ ). R emarkably, with the CoM 0 catalysts just the opposite behavior was observed and the activity decreased with an increasing number of acid sites.

The product selectivity was also affected by the presence of acid sites. B esides such usual HDS products as cis- and 

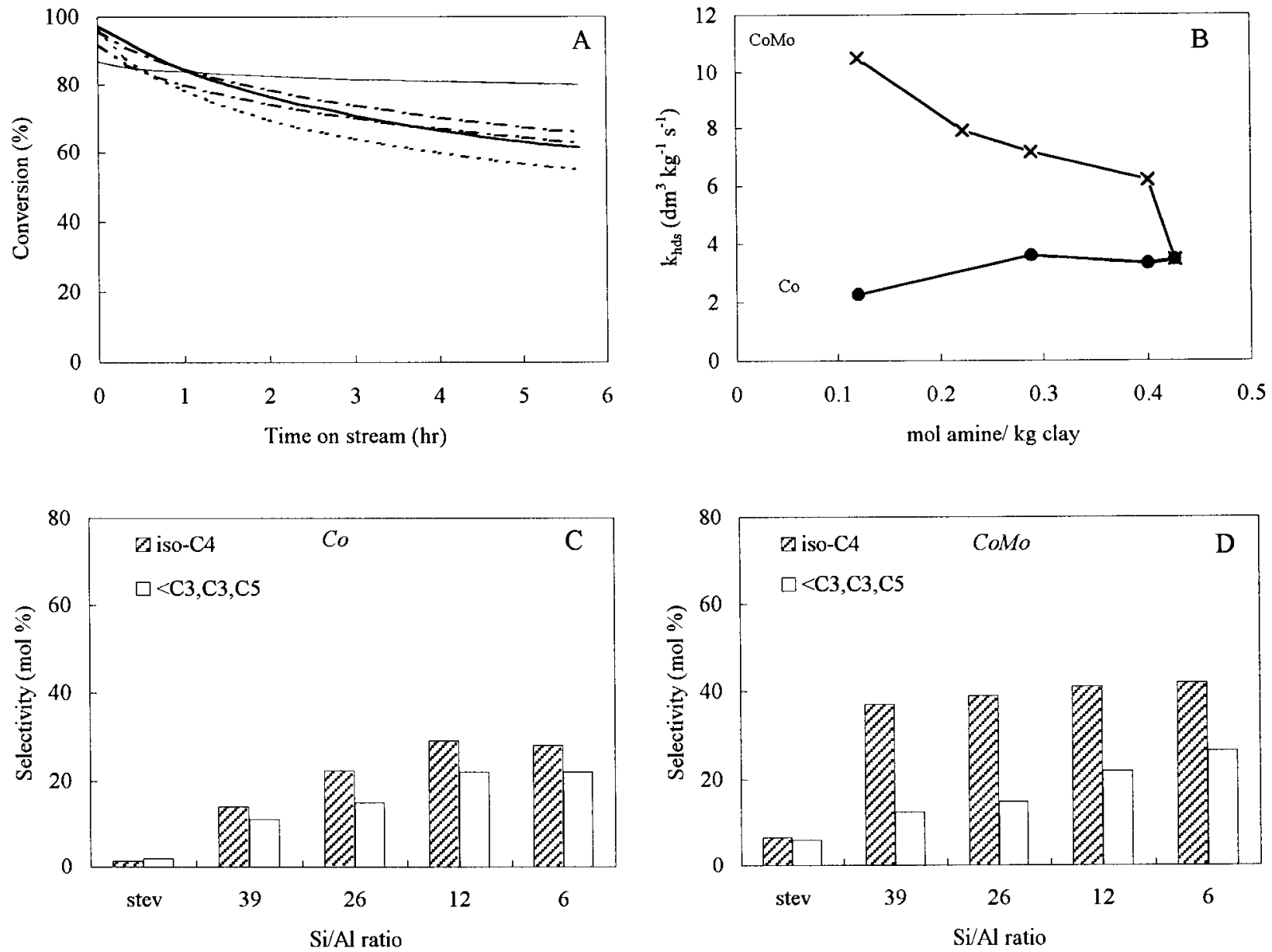

FIG. 2. (A) Thiophene conversion of the sulfided Co catalysts versus time on stream: stevensite (thin solid line) and saponites with Si/A I ratios of 39 (lower - -), 26 (upper - -), 12 (- - ), and 6 (thick solid line) (space velocity $3000 \mathrm{~h}^{-1}$ ). (B) First-order reaction rate constant $\mathrm{K}_{\mathrm{HDS}}$ for thiophene HDS at $673 \mathrm{~K}$ of the Co (closed circles) and CoM o clays (crosses) versus number of acid sites determined by TPD-TGA of n-propylamine. (C) Selectivity toward iso-butane and ( $\angle \mathrm{C} 3, \mathrm{C} 3, \mathrm{C} 5)$ of sulfided Co catalysts at $90 \%$ thiophene conversion. (D) Selectivity toward iso-butane and ( $<$ C 3 , C 3, C5) of sulfided CoM o catalysts at $100 \%$ thiophene conversion.

trans-butene and butane, iso-butane and <C 3, C3, and C5 products were also observed. These latter compounds can be formed through acid catalyzed reactions. D ue to their similar retention times the $\mathrm{GC}$ peaks of 1-butene and isobutene could not be separated and the individual presence of the two compounds could not be determined. A s demonstrated in Figs. $2 \mathrm{c}$ and $2 \mathrm{~d}$ the selectivity after 2 min time on stream toward iso-butane and $\angle \mathrm{C} 3, \mathrm{C} 3$, and $\mathrm{C} 5$, measured at conversions between 90 and $100 \%$, was on the whole found to increase with increasing support acidity. H owever, since the conversion level was above $90 \%$ it is not permitted to draw any conclusions from this. To study whether the observed iso-butane was produced by hydrogenation of iso-butene or by isomerization of butane an experiment was performed under exactly the same conditions with a feed of $1 \%$ butane in A r. N o conversion was observed, indicating that iso-butane in the HDS of thiophene is produced by hydrogenation of iso-butene.

\section{$H$ ydrocracking of n-D ecane}

The performance in the hydrocracking of n-decane of the clay catalysts was found to be related to both the Si/A I ratio of the support and the hydrogenation capacity of the metal sulfide. Figure 3 represents the first-order rate constant $\mathrm{K}_{\mathrm{HYC}}$ (calculated according to $\mathrm{Eq}$. [1]) versus the number of acid sites determined with TPD-TG A of n-propylamine. The activity of the catalysts generally increased with an increasing degree of substitution of Si by A I. R emarkably, the stevensite samples, with no substitution of Si by Al, displayed a considerable activity. The CoM o catalysts were more active than the Co catalysts with comparable Si/A I ratios. A s with thiophene HDS the catalysts suffered from deactivation and reached similar levels of conversion after $12 \mathrm{~h}$ on stream. The impregnated Co catalysts all deactivated to conversions of about $20 \%$ (stevensite at around $10 \%$ ). The CoM o samples reached conversion levels of 


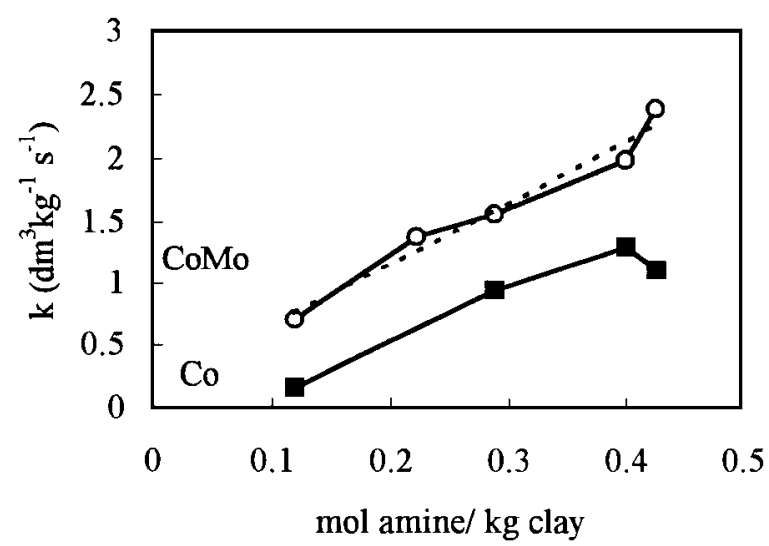

FIG. 3. First-order reaction rate constant for $n$-decane hydrocracking $\mathrm{K}_{\mathrm{HYC}}$ at $673 \mathrm{~K}$ of the $\mathrm{Co}$ (squares) and CoM o catalysts (open circles) versus number of acid sites determined by TPD-TG A of n-propylamine.

about 30\% (stevensite 20\% ). The space velocity in these experiments was $3000 \mathrm{~h}^{-1}$.

To compare the selectivity of the different catalysts the effect of the conversion and the temperature on the selectivity was investigated. Figures $4 \mathrm{~A}$ and $4 \mathrm{~B}$ compare the selectivity of the $\mathrm{CoM}$ o catalyst with a Si/A I ratio of 6 at two different level sof conversion ( 45 and $90 \%$ ). With rising conversion the selectivity toward C 3 hydrocarbons increased. $\mathrm{H}$ owever, although the conversion differs by a factor 2 the
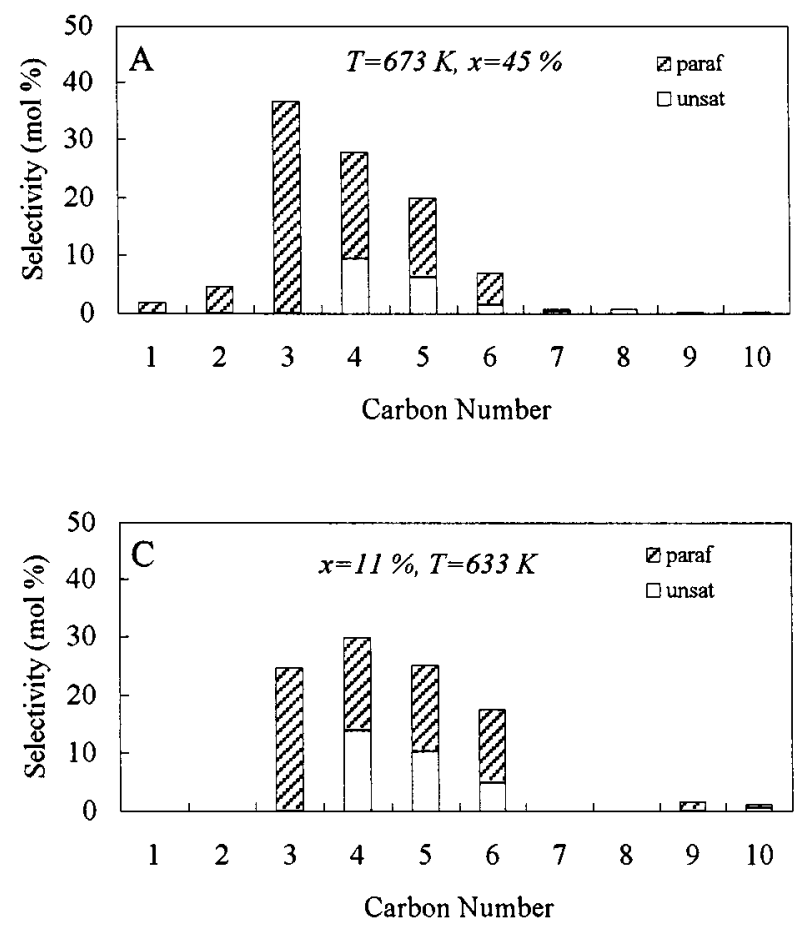

selectivity only rises about $2.5 \%$. The effect of the conversion on the selectivity toward unsaturated products is more pronounced. A sharp decrease is observed with increasing conversion or longer contact times. The effect of the temperature on the selectivity is demonstrated in Figs. 4B and $5 \mathrm{C}$ for the same sample after $12 \mathrm{~h}$ of stabilization at $673 \mathrm{~K}$. D ecreasing the reaction temperature from 673 to $633 \mathrm{~K}$ changes the selectivity pattern drastically. The selectivity toward C3 decreases from 31 to $22 \%$, balanced by a higher selectivity toward the heavier hydrocarbons (>C3). A Iso less unsaturated compounds are observed at $633 \mathrm{~K}$.

The influence of the support acidity on the selectivity is shown in Fig. 5 with the CoM o catalysts. The selectivity toward C 3 gradually drops from 37 to $22 \%$ on changing the $\mathrm{Si} / \mathrm{A}$ I ratio from 6 to 39. A s was demonstrated above, these changes are not likely to be caused by the different levels of conversion ( 46 vs $30 \%$ ), since such a change in conversion only causes variations in selectivity of $2-3 \%$. The selectivity pattern of the stevensite sample is quite different from that of the saponite samples; it has a much more even distribution over the number of carbon atoms and a reasonable production of isomerized C 10 compounds. With the $\mathrm{Co}$ saponites no changes in selectivity were observed as a function of the Si/A I ratio. The Co saponite samples all exhibited a product selectivity similar to that of the CoM 0 sample with a Si/A I ratio of 6 (Fig. 5A ). The stevensite Co
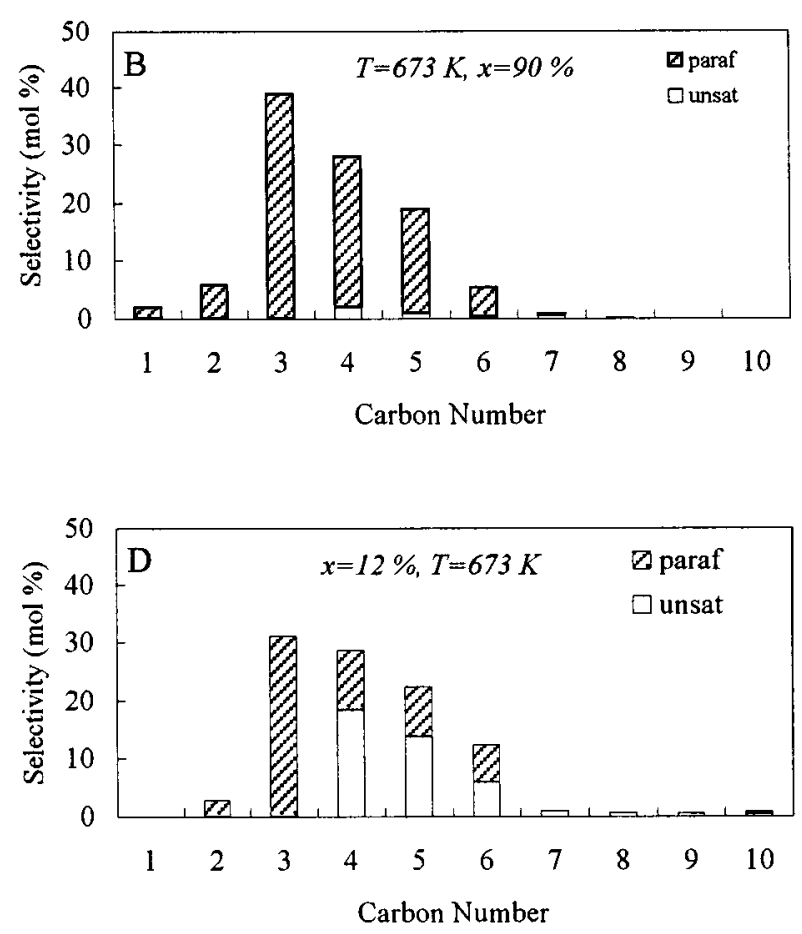

FIG. 4. Selectivity towards C $1-C 10$ hydrocarbons of $\mathrm{CoM}$ o/saponite Si/A I = 6 in $\mathrm{n}$-decane conversion after 2 min on stream at conversions of (A ) $45 \%$ and (B) $90 \%$. Selectivity of CoM o/saponite Si/A I = 6 in n-decane conversion after stabilization at $673 \mathrm{~K}$ (C) at $633 \mathrm{~K}$ ( $11 \%$ conversion) and (D) at $673 \mathrm{~K}(12 \%$ conversion). 

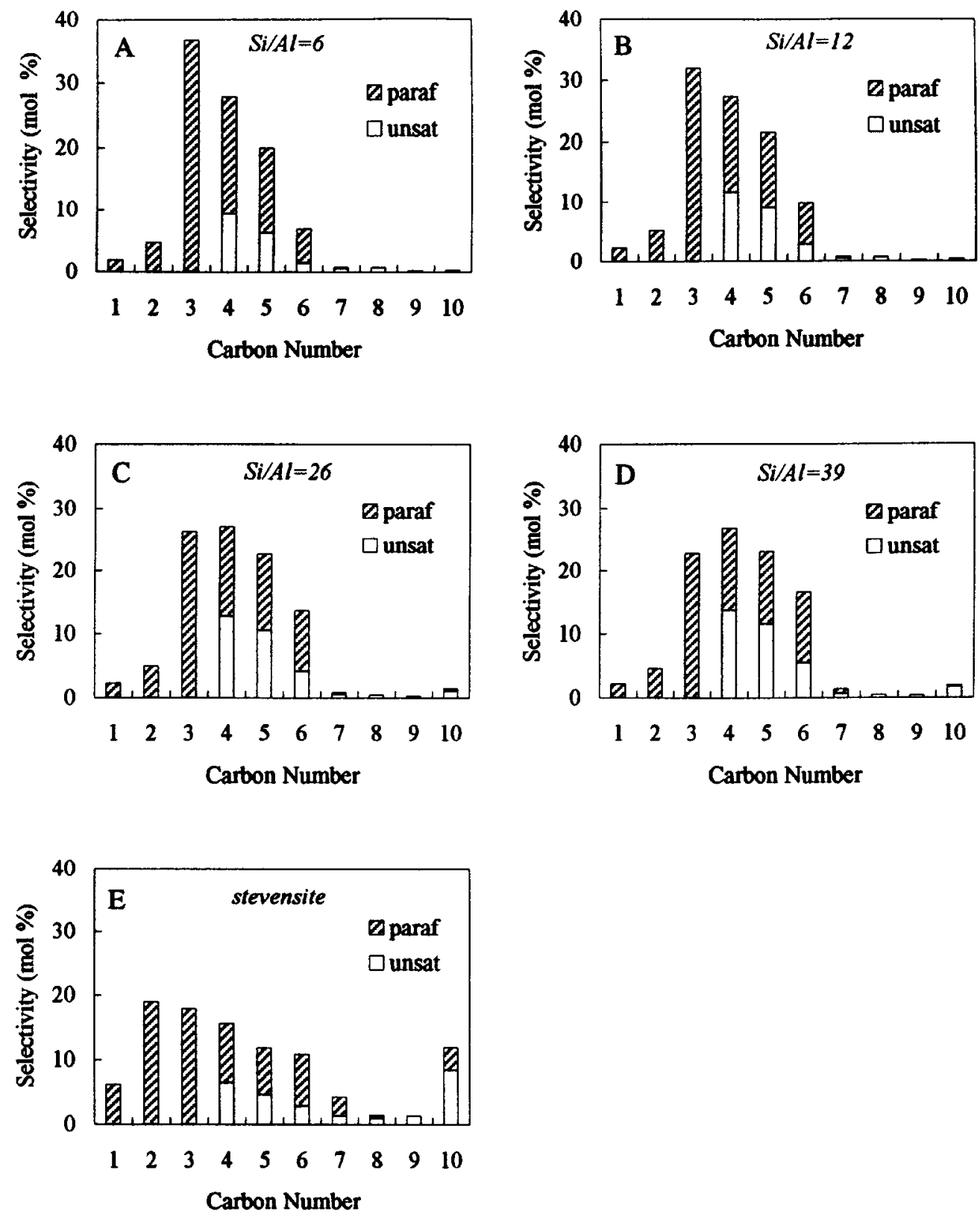

FIG . 5. Selectivity toward C $1-C 10$ hydrocarbons of the CoM o clays in n-decane conversion after 2 min on stream; Si/A I ratios of (A) 6 ( $46 \%$ conversion), (B) 12 (38\%), (C) 26 (35\%), (D) 39 (30\%), and (E) stevensite (30\%).

catalyst revealed a product selectivity resembling that of the CoM o stevensite.

Finally, the activity of the unloaded saponites was tested. The activity increased with increasing support acidity. The first-order rate constant $\mathrm{k}_{\mathrm{HY}}$ of the saponite with a Si/A I ratio 6 amounted to $0.2 \mathrm{dm}^{3} / \mathrm{kg} \cdot \mathrm{s}$, considerably lower than that of the impregnated samples. It was observed that removal of $\mathrm{H}_{2}$ from the feed ( $50 \mathrm{ml} \mathrm{Ar}$ instead) had no effect on the conversion. This indicates that over the unloaded supports cracking takes place instead of hydrocracking.
Temperature P rogrammed $\mathrm{H}$ ydrocracking

Surprisingly, when the activity was measured as a function of decreasing reaction temperature a maximum in the conversion was found in the temperature region around $523 \mathrm{~K}$. In order to study this phenomenon with catalysts that had not suffered from deactivation, conversion curves were recorded at ascending temperatures between 393 and $673 \mathrm{~K}$ with freshly sulfided samples. A s displayed in Fig. $6 \mathrm{~A}$ for the CoM o catalysts the conversion reached an optimum at about $523 \mathrm{~K}$, the maximum value rising with an increasing 

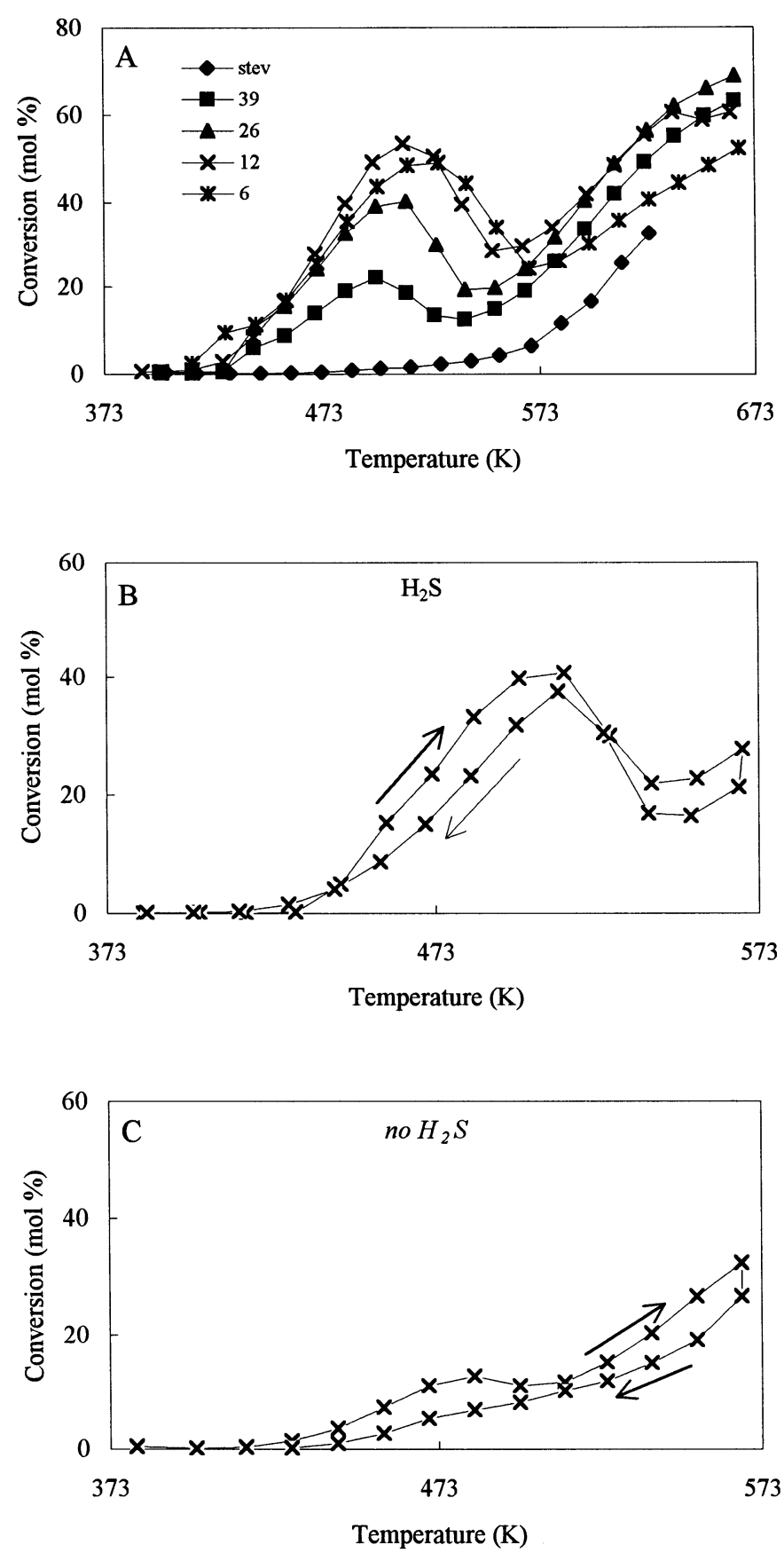

FIG. 6. (A) Conversion of $n$-decane (space velocity $3000 \mathrm{~h}^{-1}$ ) of the various sulfided $\mathrm{CoM} O$ catalysts measured at ascending temperatures. (B) Conversion of $\mathrm{n}$-decane (space velocity $3000 \mathrm{~h}^{-1}$ ) measured at ascending and descending temperatures of the $\mathrm{CoM}$ o/saponite $\mathrm{Si} / \mathrm{AI}=12$ with $\mathrm{H}_{2} \mathrm{~S}$ in the feed. (C) A s Fig. $7 \mathrm{~b}$ without $\mathrm{H}_{2} \mathrm{~S}$ in the feed.

degree of substitution of Si by A I. B eyond 573K the conversion increased again, but did not follow a first-order conversion curve. This concave shape of the curves is ascribed to deactivation of the catalysts at higher temperatures due to coke formation. With the H D S experiments it was observed that the catalyst activity could be restored by an oxidative regeneration, indicating the occurrence of coking. Hence, it is reasonably assumed that a similar mechanism of deactivation takes in the hydrocracking of $\mathrm{n}$-decane at elevated temperatures.

Since the stevensite sample did not show any activity at low temperatures the maxima in the conversion curves must be related to the presence of the acid sites on the saponite supports. Since it is well known that dehydroxylation of the support can lead to the loss of Brønsted sites the conversion was also measured at descending temperatures to study whether the conversion drop between 523 and $573 \mathrm{~K}$ was reversible. To ensure that the feed contained no water that could readsorb during cooling down, the gas stream was dried over Sicapent (M erck). A s shown in Fig. 6B the maximum in the conversion curve was almost completely restored on cooling down, indicating that dehydroxylation was not likely to cause the optimum in the conversion. In contrast to this, it turned out that omission of $\mathrm{H}_{2} \mathrm{~S}$ from the feed strongly affected the course of the activity (Fig. 6C). A t ascending temperatures the maximum conversion attained a value of only $14 \%$, while at descending temperatures the activity reached a maximum of only $5 \%$ conversion. The observed activity between 423 and $573 \mathrm{~K}$ is obviously brought about by a combination of the acid sites on the support and the presence of $\mathrm{H}_{2} \mathrm{~S}$ in the feed. Finally, when the sulfided catalyst was exposed to water vapor before reaction the activity in the region of $523 \mathrm{~K}$ was completely lost, indicating poisoning of the acid sites by water adsorption.

\section{DISCUSSION}

\section{$D$ ispersion and $L$ ocation of $M$ etal Sulfide Particles}

In the $\mathrm{Co}$ and CoM o catalysts a high dispersion of both the supported cobalt sulfide and the molybdenum sulfide phase independent of the Si/A I ratio of the support was found. U nfortunately, the cobalt sulfide phase in the CoM 0 catalyst was not characterized with EXA FS at the time and no data are available on its dispersion.

It is known that $\mathrm{M} o$ hydrolyzes in aqueous solutions to form $\left(\mathrm{M} \mathrm{O}_{7} \mathrm{O}_{24}\right)^{6-}$ and $\left(\mathrm{M} \mathrm{OO}_{4}\right)^{2-}$ ions while $\mathrm{Co}$ occurs as $\mathrm{CoOH}^{+}$or $\mathrm{CO}_{2} \mathrm{OH}^{3+}$ in aqueous solutions (40). A pparently, since both the cobalt sulfide and the molybdenum sulfide dispersion are quite high, a good interaction exists between the surface of the saponite sheets and both positively and negatively charged ions. This dual behavior might be explained by the existence of a positive electrical double layer on the edges of the clay particles and a negative double layer on the faces (top and bottom planes) of the clay platelets (41). In this model the positively charged cobalt ions are thus assumed to adsorb preferentially on the faces of the clay platelets while the negatively charged molybdenum ions interact with the positively charged edges of the clay platelets. 


\section{H D S A ctivity and Product Selectivity}

The thiophene HDS test results show that the initial HDS activity of the $\mathrm{Co}$ catalysts considerably increases when saponite is used as support instead of stevensite. Since the dispersion of the cobalt sulfide phase is similar this must be related to the acidic nature of the saponite. A positive correlation between the acidity of the support and the HDS activity was also reported by Welters et al. (42) in a study of the HDS performance of metal sulfides supported on $\mathrm{H}(\mathrm{x}) \mathrm{N}$ aY, $\mathrm{ZSM}-5$, and $\mathrm{H}-\mathrm{U}$ SY zeolites. Several possibilities were discussed as an enhanced adsorption of thiophene in the zeolite pores, acceleration of the rate determining step through involvement of protons, and formation of a higher number of $\mathrm{SH}$ groups on the metal sulfide phase. A Ithough we cannot present any evidence another possibility is that the acidity of the support affects the catalytic properties of the supported metal sulfide particles through small changes of the electronic structure of the metal sulfides.

R emarkably, the initial activity of the CoM o catalysts clearly decreases with increasing support acidity, in contrast with the work of Welters et al. (42) and the findings with the Co catalysts. In the CoM o catalyst the promoter atoms can either be present on the faces of the clay platelets or be associated with $\mathrm{M} \mathrm{o}$ in the very active "Co-M o-S" phase. D ecreasing the Si/A I ratio of the support will increase the negative charge on the clay platelets, enhancing the adsorption of the positively charged $\mathrm{Co}$ ions on the clay facesaway from the M o. Since C o-M o-S is known to be more active than the sum of separate Mo and $\mathrm{Co}$ sulfides, this might explain the decrease in activity with a higher support acidity. I nterestingly, in the hydrocracking experiments the opposite behavior is observed, i.e., the activity of the CoM o catalysts increases with increasing support acidity. This can be ascribed to either an increased activity of the hydrogenation sites(assumed that for hydrogenation the effect of synergy between $\mathrm{Co}$ and $\mathrm{Mo}$ in a Co-M o-S structure is low) or to a larger number of acid sites. The latter explanation is supported by the linear relationship between the number of acid sites and the rate of the hydrocracking reaction (vide infra).

The detection of $<\mathrm{C} 3, \mathrm{C} 3$, and $\mathrm{C} 5$ as reaction products is in accordance with the results of Houzvicka et al. (43) in which the authors demonstrated that B rønsted acid sites are the active sites in the skeletal isomerization of $n$-butene. $\mathrm{n}$-B utene formed in the HDS of thiophene is isomerized to iso-butene over the acid sites of the support. Subsequently, the iso-butene is hydrogenated to iso-butane. The formation of $\angle \mathrm{C} 3, \mathrm{C} 3$, and $\mathrm{C} 5$ proceeds through dimerization of C4 followed by cracking (44). The dimerization of C 4 also gives rise to oligomerization, resulting in coking of the catalysts and the observed initial deactivation.

\section{B alance between $\mathrm{H}$ ydrogenation and $\mathrm{A}$ cid Sites}

The activity in the hydrocracking of $n$-decane rises with decreasing Si/A I ratios. With the CoM o samples an almost linear relationship is observed between the number of acid sites and the pseudo-first-order rate constant $k_{\text {HYc }}$. In the classical mechanism of bifunctional hydrocracking dehydrogenation of n-decane takes place over the hydrogenation sites followed by one or more skeletal rearrangements over the acid sites and subsequent hydrogenation of the product alkenes by the sulfide sites $(45,46)$. Provided that the (de)hydrogenation capacity is sufficiently high the rearrangements will be the rate limiting step (47). A s observed an increasing number of acid sites will thus increase the activity. $\mathrm{H}$ owever, since the activity also increases when COM OS is used instead of only $\mathrm{COS}$, in the Co catalysts the (de)hydrogenation activity is also limited.

The poor hydrogenation character of the $C o$ catalystsand even of the CoM o catalysts is reflected in the product selectivity. A part from the stevensite samples none of the catalysts are able to isomerize $n$-decane to a significant extent. A fter rearrangement of $\mathrm{C} 10$ olefines the carbenium ions are not hydrogenated but instead $\beta$-scission of the di- and tribranched isomers occurs to yield cracked products $(48,49)$. The primary $\mathrm{C} 6 / \mathrm{C} 7$ primary products can undergo consecutive cracking as is shown by the relatively high amounts of propane. With the Co catalysts the hydrogenation function is even so poor that the Si/A I ratio of the support does not have any significant effect on the product selectivity. With the CoM o catalysts, containing a stronger hydrogenation function, the Si/A I ratio does influence the product selectivity. The catalysts with high $\mathrm{Si} / \mathrm{A}$ I ratios produce significantly less propane than the ones with low Si/A I ratios. A pparently, the primary cracking products are hydrogenated and leave the catalyst surface before they are cracked further. The CoM o catalyst with a Si/A I ratio of 39 displays the best balance between the hydrogenation and acid function although the amount of isomerized C 10 is still low $(<5 \%)$.

R emarkably, the stevensite samples show a reasonable activity coupled with a rather high degree of isomerization. The high selectivity toward isomerization might be caused by the lower number of acid sites or by their weaker acid strength. In stevensites there is no substitution of Si by A I and the acid sites are terminal hydroxyl groups at the edges of the clay platelets. These terminal hydroxyl groups are generally thought to be less acidic than the protonated Si-O-A I bridges. A Iternatively, the high isomerisation activity can be associated with the metal sulfide phase. It is known that metal sulfide particles contain -SH groups that can act as B rønsted acid sites and are able to participate in hydrocracking reactions (50).

A sillustrated in Figs. 4C and 4D the temperature also has a significant effect on the product selectivity. L ower temperatures suppress secondary cracking reactions demonstrated by the lower amounts of propane formed. H owever, a lower reaction temperature does not greatly enhance the selectivity toward hydroisomerization. To achieve that goal, a stronger hydrogenation function is needed, for example a higher metal sulfide loading or a noble metal. 


\section{G eneration of A cidity by $\mathrm{H}_{2} \mathrm{~S}$}

The observed maximum at low temperatures in the hydrocracking activity seems to be due to a combination of $\mathrm{Si}-\mathrm{OH}-\mathrm{A}$ I sites with $\mathrm{H}_{2} \mathrm{~S}$. The results clearly demonstrate a relation between activity and $\mathrm{Si} / \mathrm{A}$ I ratio and the influence of the partial pressure of $\mathrm{H}_{2} \mathrm{~S}$. A dditionally, the involvement of $\mathrm{Si}-\mathrm{OH}-\mathrm{A}$ I sites is also suggested by the loss of activity after prior exposure to water vapor. Water can act as a poison by irreversible adsorption on the acid sites (at least at low temperature).

The formation of Brønsted acid sites by reversible adsorption of $\mathrm{H}_{2} \mathrm{~S}$ has previously been reported by Sugioka et al. (51) for various alkali metal zeolites. These authors proposed that the generation of these acid sites is caused by nondissociative adsorption of $\mathrm{H}_{2} \mathrm{~S}$ as $\mathrm{H}-\mathrm{S}-\mathrm{H}$ groups exhibiting $B$ rønsted acidity. A Iternatively, dissociative adsorption of $\mathrm{H}_{2} \mathrm{~S}$ was proposed over $\mathrm{Na}^{+}$ions, leading to excess protons forming new acidic $-\mathrm{OH}$ groups. (52). A (reversible) adsorption of $\mathrm{H}_{2} \mathrm{~S}$ creating $\mathrm{B}$ rønsted activity may also occur in saponites. H owever, that the created acid sites are stronger than the original acid sites seems not logical and cannot be explained. I nterestingly, in a recent paper by Stumbo et al. (53) on physical mixtures of $\mathrm{CoMo} / \mathrm{SiO}_{2}$ and silica-aluminas, the creation of acid $B$ rønsted sites was proposed to occur by migration of spillover species from the CoM o catalyst to the silica-aluminas. This process was accelerated in the presence of both $\mathrm{H}_{2} \mathrm{O}$ and $\mathrm{H}_{2} \mathrm{~S}$. Such a migration of spillover species might also take place in the saponite catalysts.

A Itogether, the current experimental results do not allow to find a satisfying explanation for the hydrocracking activity at low temperature. H owever, the results are intriguing and indicate the complexity of hydrocracking induced by the presence of a variety of gaseous and solid components.

\section{CONCLUSIONS}

In thisstudy the relation between the performance of clay supported (Co)M o sulfides and the acidity of the support, varied through means of the Si/A I ratio, was investigated. In the hydrodesulfurization of thiophene an increasing number of B rønsted acid sites affects both the activity and selectivity. With Co catalyst a small increase in the initial activity is observed when $\mathrm{Si}$ is substituted for A I. However, with CoM o catalysts a decrease of the initial HDS activity with decreasing Si/A I ratios is observed. This observation is ascribed to a lower relative amount of $\mathrm{Co}$-M o-S due to preferred adsorption of $\mathrm{Co}$ ions on the faces of the saponite platelets and adsorption of $\mathrm{Mo}$ on their edges. The acid sites on the support are able to isomerize n-butene into isobutene with high yields. Further, a clear relationship was found between the number of acid sites and the selectivity toward cracking products formed through acid catalyzed reactions.
In the hydrocracking of $n$-decane the activity of the catalysts rises with an increasing degree of substitution of Si by A I in the support. W ith CoM o impregnated samples a linear relationship is observed between the number of $B$ rønsted sites and the first-order reaction rate constant. A II cobalt sulfide catalysts and the CoM o catalysts with low Si/A I ratios are deficient in their hydrogenation capacity, leading to a rather high selectivity toward secondary cracking products. Further, the ratio between the number of hydrogenation sites and the number (and possibly strength) of acid sites determines the degree of hydroisomerization versus hydrocracking.

Finally, it was observed that interaction of $\mathrm{H}_{2} \mathrm{~S}$ with the support leads to extra activity at low temperature in the hydrocracking of $n$-decane. The positive relation between the degree of Si for A I substitution and the "low-temperature" activity points to the involvement of the $\mathrm{Si}-\mathrm{OH}-\mathrm{A}$ I groups on the surface of the saponite support.

\section{REFERENCES}

1. Figueras, F., Catal. Rev. Sci. Eng. 30, 457 (1988).

2. M ing-Y uan, H ., Z hongui, L ., and E nze, M ., Catal. Today 2, 321 (1988).

3. Burch, R., and Warburton, C. I., J. Catal. 97, 503 (1986).

4. M okaya, R., and Jones, W., J. Catal. 153, 76 (1995).

5. M arco, F., and R osa-B russin, D., Catal. Rev. Sci. Eng. 37, 1 (1995).

6. Ward, J. W., Fuel Proc. Technol. 35, 55 (1993).

7. Maxwell, I. E., and Stork, W. H. J., Stud. Surf. Sci. Catal. 58, 571 (1991).

8. Welters, W. J. J., van der Waerden, O. H., de Beer, V. H. J., and van Santen, R. A ., Ind. Eng. Chem. Res. 34, 1166 (1995).

9. L eglise, J., M anoli, J. M ., Potvin, C., D jega-M ariadassou, and Cornet, D., J. Catal. 152, 275 (1995).

10. Cid, R ., G il L lambias, F. ., G onzalez, M ., and L opez A gudo, A ., Catal. L ett. 24, 147 (1994).

11. Welters, W. J. J., Vorbeck, G., Zandbergen, H. W., de Haan, J. W., de B eer, V. H . J., and van Santen, R. A ., J. Catal. 150, 155 (1994).

12. K loprogge, J. T., Welters, W. J. J., B ooy, E ., de B eer, V. H. J., van Santen, R. A ., and G eus, J. W., A ppl. Catal. A 97, 77 (1993).

13. Sharma, R. K., and Olson, E. E., Prepr. A m. Chem. Soc. Div. Fuel Chem. 39, 702 (1994).

14. Sychev, M., de B eer, V. H. J., van Santen, R. A., Prihod'ko, R., and Goncharuk, V., Stud. Surf. Sci. Catal. 84, 267 (1994).

15. Sychev, M., Kostoglod, N., van Oers, E. M., de Beer, V. H. J., van Santen, R. A ., Kornatoski, J., and R ozwadowski, M., Stud. Surf. Sci. Catal. 94, 39 (1995).

16. Swift, H. E., and Black, E. R ., Prepr. A m. Chem. Soc. D iv. Pet. Chem. 19, 7 (1974).

17. Doblin, C., Mathews, J. F., and Turney, T. W., A ppl. Catal. 70, 197 (1991).

18. K loprogge, J. T., B ooy, E ., Janssen, J. B. H ., and G eus, J. W., C atal. L ett. 29, 293 (1994).

19. M olina, R., M oreno, S., Vieira-Coelho, A., M artens, J. A ., Jacobs, P. A ., and Poncelet, G., J. Catal. 148, 304 (1994).

20. O ccelli, M. L ., and R ennard, R. J., Catal. Today 2, 309 (1988).

21. M onnier, J., Charland, J. P., B rown, J. R ., and W ilson, M . F., Stud. Surf. Sci. Catal. 75, 1942 (1993).

22. M in, E., Stud. Surf. Sci. Catal. 83, 443 (1994).

23. Vogels, R. J. M. J., Kerkhoffs, M. J. H. V., and Geus, J. W., Stud. Surf. Sci. Catal. 91, 1153 (1995). 
24. L eliveld, R. G., H uyben, W. C. A ., van Dillen, A. J., G eus, J. W., and Koningsberger, D. C., Stud. Surf. Sci. Catal. 106, 137 (1997).

25. A Ivarez, F., R ibeiro, F. R ., Perot, G., Thomazeau, C., and G uisnet, M ., J. Catal. 162, 179 (1996).

26. Vaarkamp, M., Mojet, B. L., Kappers, M. J., Miller, J. T., and Koningsberger, D. C., J. Phys. Chem. 99, 16067 (1995).

27. van Zon, J. B. A . D., K oningsberger, D. C., van B lik, H . F. J., and Sayers, D. E., J. Chem. Phys. 82, 5742 (1985).

28. Bouwens, S. M. A. M., van Veen, J. A. R., Koningsberger, D. C., de Beer, V. H. J., and Prins, R ., J. Phys. Chem. 95, 123 (1991).

29. B ouwens, S. M. A . M ., Prins, R ., de B eer, V. H . J., and Koningsberger, D. C., J. Phys. Chem. 94, 3711 (1990).

30. D uivenoorden, F. B. M., Koningsberger, D. C., U h, Y. S., and G ates, B. C., J. A m.Chem. Soc. 108, 6524 (1986).

31. Kampers, F. W. H., Engelen, C. W. R., van Hooff, J. H. C., and Koningsberger, D. C., J. P hys. Chem. 94, 8574 (1990).

32. Vaarkamp, M., L inders, J. C., and Koningsberger, D. C., P hysica B 208 \& 209, 159 (1995).

33. Leliveld, R. G., van Dillen, A. J., G eus, J. W., and Koningsberger, D. C., J. Catal. 175, 108 (1998).

34. L eliveld, R. G., van Dillen, A. J., Geus, J. W., and Koningsberger, D. C., J. Catal. 165, 184 (1997).

35. Shido, T., and Prins, R., J. Phys. Chem. B 102, 8426 (1998).

36. Leliveld, R. G., van Dillen, A. J., G eus, J. W., and Koningsberger, D. C., J. Catal. 171, 115 (1997).

37. Parrillo, D. J., A damo, A. T., Kokotailo, G. T., and Gorte, R. J., A ppl. Catal. 67, 107 (1990).

38. Tittensor, J. G., G orte, R. J., and Chapman, D. M., J. Catal. 138, 714 (1992).
39. Leliveld, R. G., Kerkhoffs, M. J. H. V., Broersma, A., van Dillen, A. J., G eus, J. W., and Koningsberger, D. C., J. Chem. Soc. Faraday Trans. 94, 315 (1998).

40. B aes, C. F., and M esmer, R . E ., in "The H ydrolysis of Cations" WileyInterscience (1976).

41. van OIphen, $\mathrm{H}$., in "A n Introduction to Clay Colloid Chemistry." Wiley-Interscience, N ew Y ork, 1977.

42. Welters, W. J. J., de B eer, V. H. J., and van Santen, R. A ., A ppl. Catal. A 119, 253 (1994).

43. H ouzvicka, J., and Ponec, V., A ppl. Catal. A 145, 95 (1996).

44. H ouzvicka, J., K lik, R., Kubelkova, L., and Ponec, V., A ppl. Catal. A 150, 101 (1997).

45. Coonradt, M. L., and G arwood, W. E., Ind. Eng. Chem. Prod. Res. D ev. 3, 38 (1964).

46. Weisz, P. B., A dv. Catal. 13, 137 (1962).

47. Pichler, H., Schultz, H., R eitmeyer, H. O., and Weitkamp, J., E rdöl, Kohle E rdgas Petrochem. 25, 494 (1972).

48. M artens, J. A ., Jacobs, P. A ., and Weitkamp, J., A ppl. Catal. 20, 239 (1986).

49. A Ivarez, F., R ibeiro, F. R ., Perot, G., Thomazeau, C., and G uisnet, M ., J. Catal. 162, 179 (1996).

50. Topsøe, H., Clausen, B. S., and M assoth, F. E., in "H ydrotreating Catalysis-Science and Technology," Vol. 11. Springer-Verlag, Berlin, 1996.

51. Sugioka, M ., A misawa, M ., and Sato, K ., Stud. Surf. Sci. Catal. 84, 1603 (1994).

52. N arbeshuber, T. F., Ph.D. thesis, E nschede, 1994.

53. Stumbo, A . M ., G range, P., and D elmon, B., Stud. Surf. Sci. Catal. 112, 211 (1997) 